\title{
Transient Isolated Thyrotropin Deficiency Associated with Cavernous Sinus Syndrome
}

\author{
Masayuki Ohtaka, Kazutaka Haraguchi, Hiromichi Shimoda, Toyoshi Endo and Toshimasa Onaya
}

The cause and course of isolated thyrotropin (TSH) deficiency are not well understood. We report a 65-year-old man with a transient, probable isolated TSH deficiency associated with cavernous sinus syndrome secondary to tympanitis. On his admission, serum TSH and triiodothyronine levels were very low. No TSH response to thyrotropin releasing hormone (TRH) was observed. However, 6 years later, TSH response to TRH was restored. The present case showed that inflammation in the cavernous sinus could be one of the causes of TSH deficiency. Further, it demonstrated that TSH deficiency is not always permanent and the reevaluation of pituitary function is necessary.

(Internal Medicine 37: 300-303, 1998)

Key words: lymphocytic hypophysitis, secondary hypothyroidism

\section{Introduction}

Isolated thyrotropin (TSH) deficiency is a rare disease that was first reported by Schuman in 1953 (1). However, its pathogenesis still remains unclear and the long-term outcome of this disease is unknown. Here, we describe a patient with isolated TSH deficiency which seemed to be accompanied by cavernous sinus syndrome. After treatment with glucocorticoid and thyroid hormone, the serum TSH levels gradually returned to normal. Furthermore, the serum level of TSH and the TSH response to thyrotropin releasing hormone (TRH) remained normal 6 months after discontinuation of thyroid hormone therapy. To our knowledge, this is the first report of transient, isolated TSH deficiency in man.

For editorial comment, see also p 231.

\section{Case Report}

A 65-year-old man developed a continuous left zygomatic and postauricular pain after extraction of a tooth in August 1988. Five weeks later, left blepharoptosis, external ophthalmoplegia and facial sensory disturbance became apparent. He was admitted to Yamanashi Medical University Hospital in October 1988. Soon after admission, left otorrhea appeared. Since antibiotics were not effective in reducing neurologic abnormalities, intravenous administration of dexamethazone (12 mg/day, q 8 hours) was started under the diagnosis of cavernous sinus syndrome secondary to left tympanitis. His neurologic findings subsequently improved. His past medical history was remarkable for a 7-year history of non-insulindependent diabetes mellitus, but he had been receiving no medication during the preceding year. There was no family history of endocrine or autoimmune disease. On physical examination, he had ptosis of his left eye. A dot hemorrhage in his right eye ground was observed. The thyroid gland was not enlarged. His chest was clear to auscultation. On neurologic examination, he was well-oriented, but left oculomotor, trochlear, abducens and trigeminal nerve palsies were detected. Deep tendon reflexes were absent for both patellar and Achilles' tendons.

A urinalysis was significant for glucosuria, but no proteinuria was detected. Hemoglobin level was $10.9 \mathrm{mg} / \mathrm{dl}$, red blood cell count $331 \times 10^{4} / \mu \mathrm{l}$, white blood cell count $5,800 / \mu \mathrm{l}$, platelet count $30.1 \times 10^{4} / \mu$ l. Fasting blood serum total cholesterol and triglyceride concentrations were $161 \mathrm{mg} / \mathrm{dl}$ and $80 \mathrm{mg} / \mathrm{dl}$, respectively. Glycosylated hemoglobin $A_{1 C}$ was $9.6 \%$. Endocrine data are shown in Table 1. Serum TSH and triiodothyronine (T3) levels were undetectable, and serum thyroxine (T4) level was $4.8 \mu \mathrm{g} / \mathrm{dl}$. Anti-thyroglobulin antibody and microsome hemagglutinin tests were negative. Exogenous TRH administration did not elicit elevation of serum TSH (Fig. 1). Serum concentrations of prolactin after TRH challenge were 4, 54, 31,

From the Third Department of Internal Medicine, Yamanashi Medical University, Yamanashi

Received for publication May 26, 1997; Accepted for publication November 11, 1997

Reprint requests should be addressed to Dr. Toshimasa Onaya, the Third Department of Internal Medicine, Yamanashi Medical University, Tamaho, Yamanashi 409-3821 
Transient TSH Deficiency

Table 1. Endocrine Data on the First Admission

\begin{tabular}{|c|c|c|c|c|c|}
\hline Hormones & \multicolumn{2}{|c|}{ (normal range) } & \multicolumn{2}{|c|}{ Hormones } & (normal range) \\
\hline $\mathrm{LH}$ & \multicolumn{2}{|c|}{$15 \mathrm{mIU} / \mathrm{ml}(1.1 \sim 8.8)$} & \multicolumn{2}{|c|}{$\mathrm{TSH}$} & $<0.1 \mu \mathrm{U} / \mathrm{ml}(0.5 \sim 5.0)$ \\
\hline FSH & \multicolumn{2}{|c|}{$16 \mathrm{mIU} / \mathrm{ml}(1.8 \sim 13.6)$} & \multicolumn{2}{|c|}{ T3 } & $<0.3 \mathrm{ng} / \mathrm{dl}(90 \sim 190)$ \\
\hline ACTH & \multicolumn{2}{|c|}{$47 \mathrm{pg} / \mathrm{ml}(<50)$} & \multicolumn{2}{|c|}{$\mathrm{T} 4$} & $4.8 \mu \mathrm{g} / \mathrm{dl}(4.5 \sim 12.5)$ \\
\hline $\mathrm{GH}$ & \multicolumn{2}{|c|}{$2.9 \mathrm{ng} / \mathrm{ml}(<5)$} & \multicolumn{2}{|c|}{ Cortisol } & $16.8 \mu \mathrm{g} / \mathrm{dl}(5.6 \sim 21.3)$ \\
\hline PRL & \multicolumn{2}{|c|}{$4.0 \mathrm{ng} / \mathrm{ml}(3 \sim 20)$} & \multicolumn{2}{|c|}{ Urine $17 \mathrm{OHCS}$} & $4.1 \mathrm{mg} /$ day $(2.0 \sim 9.0)$ \\
\hline $\mathrm{ADH}$ & \multicolumn{2}{|c|}{$1.2 \mathrm{pg} / \mathrm{ml}(0.3 \sim 4.2)$} & \multicolumn{2}{|c|}{$17 \mathrm{KS}$} & $4.0 \mathrm{mg} /$ day $(3 \sim 8)$ \\
\hline LH-RH test & $0^{\prime}$ & $30^{\prime}$ & $60^{\prime}$ & $90^{\prime}$ & 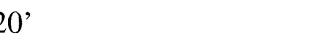 \\
\hline $\mathrm{LH}$ & 15 & 76 & 80 & 74 & $\mathrm{mIU} / \mathrm{ml}$ \\
\hline FSH & 16 & 22 & 27 & 28 & $\mathrm{mIU} / \mathrm{ml}$ \\
\hline
\end{tabular}

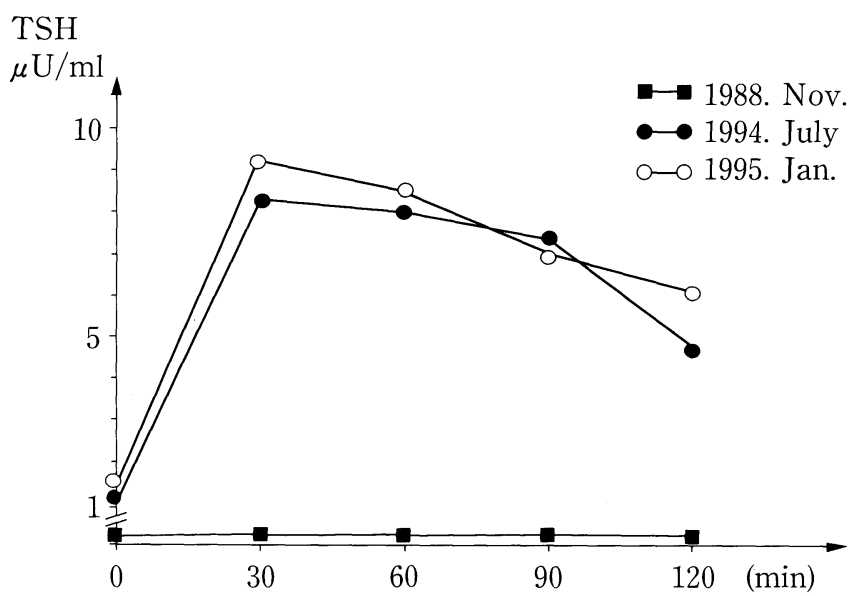

Figure 1. TSH response to TRH (500 $\mu$ g i.v.). TRH was administered and serum specimen was collected at the time indicated in the figure.

$18,12 \mathrm{ng} / \mathrm{ml}$ at $0,30,60,90$ and 120 minutes, respectively. Anterior pituitary functions are shown in Table 1 . Serum concentrations of leuteinizing hormone (LH) and follicular stimulating hormone (FSH) to exogenous LH-releasing hormone were normal. A chest X-ray revealed a normal cardiac shadow. An electrocardiogram showed sinus bradycardia. Magnetic resonance imaging revealed multiple lacunar infarctions, but the pituitary gland and hypothalamus were unremarkable (Fig. 2). A ${ }^{99 \mathrm{~m}}$ Tc-labeled bone scan revealed increased uptake in the clivus and left petrous bone (Fig. 3). Ultrasound examination of the thyroid gland was normal. He was diagnosed as having a probable isolated TSH deficiency and was subsequently treated with oral thyroxine $(50 \mu \mathrm{g} / \mathrm{day})$. $\mathrm{He}$ was also treated with insulin during the course of steroid therapy.

During a follow-up period, his serum TSH levels gradually increased (Fig. 4). The serum TSH concentration was $0.21 \mu \mathrm{U} /$ $\mathrm{ml}$ on Feb. 6, 1989. His free T3 and free T4 were $0.46 \mathrm{pg} / \mathrm{ml}$ and $0.34 \mathrm{ng} / \mathrm{dl}$, respectively. On July 26, 1990, serum TSH reached the lower normal limit. Then, he was followed in another

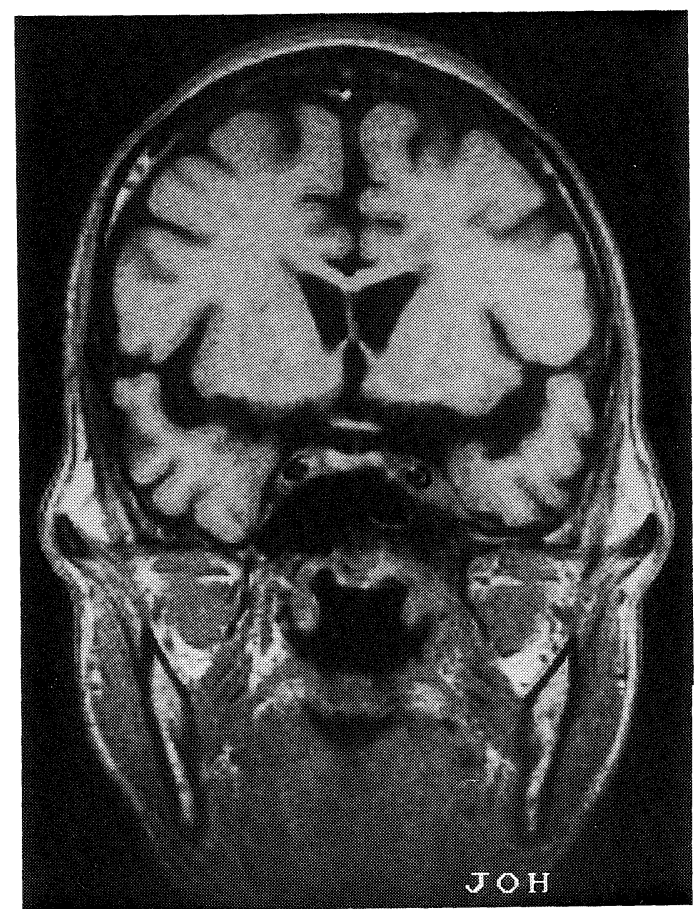

Figure 2. Magnetic resonance imaging of the head in October 1988. Multiple lacunar infarctions were found but the pituitary gland and hypothalamus were unremarkable.

hospital until 1994. He was readmitted to our hospital in July 1994 for reevaluation of pituitary functions. Two weeks after the discontinuation of thyroid hormone supplementation, serum TSH, free T3 and free T4 were $0.95 \mu \mathrm{U} / \mathrm{ml}, 2.80 \mathrm{pg} / \mathrm{ml}$ and $1.09 \mathrm{ng} / \mathrm{dl}$, respectively. The serum TSH response to exogenous TRH injection (July 12, 1994) was normal (Fig. 1).

Six months later, he demonstrated a euthyroid state in the absence of T4 supplement. Serum free T3, free T4 and TSH levels were $3.71 \mathrm{pg} / \mathrm{ml}, 1.19 \mathrm{ng} / \mathrm{dl}$ and $1.52 \mu \mathrm{U} / \mathrm{ml}$, respectively, on Jan. 10, 1995. The TSH response to exogenous TRH was normal (Fig. 4). 

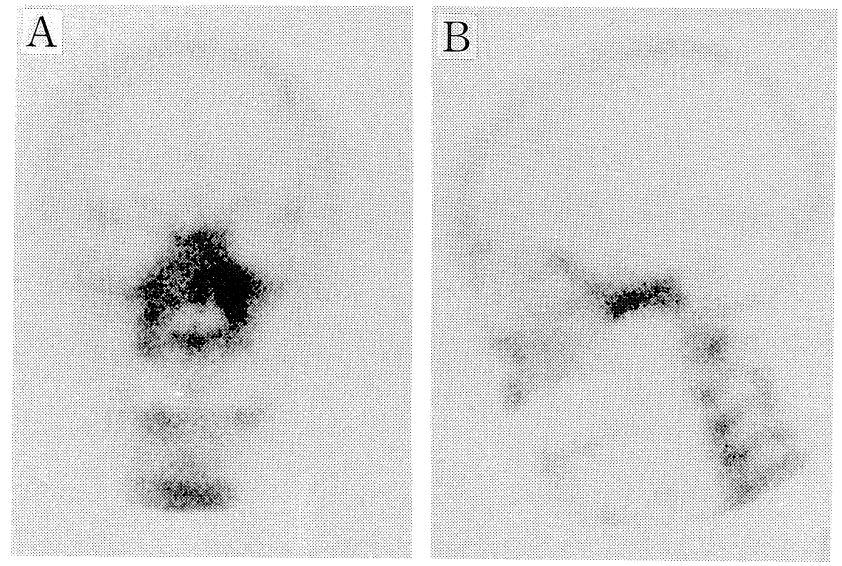

Figure 3. Bone scan of the head in October $1988 .{ }^{99} \mathrm{~m}$ Tcuptake was increased in the left clivus and petrous bone.

\section{Discussion}

Isolated TSH deficiency was first reported by Shuman in 1953 (1). Since then, several cases of isolated TSH deficiency have been reported. Isolated TSH deficiency in the adult population commonly shows absent or mild symptoms of hypothyroidism $(2,3)$. The diagnostic criteria of isolated TSH deficiency include: 1) low serum levels of thyroid hormones and $\mathrm{TSH}, 2$ ) a normal or high serum level of TRH (4), 3) lack of TSH response to exogenous TRH administration, and 4) normal secretion of other anterior pituitary hormones including a normal prolactin response to TRH. Although serum TRH was not measured in the present case, other laboratory data were compatible with isolated TSH deficiency. We did not carry out growth hormone $(\mathrm{GH})$ and adrenocorticotropic hormone (ACTH) stimulation tests, because we were in need of immediate treatment for cavernous sinus syndrome with glucocorticoid. Thus, despite normal levels of basal GH, ACTH, cortisol and urinary 17 OHCS, we may have to define this case as a probable isolated TSH deficiency. In this patient, serum T3 was undetectably low, and serum T4 was a little above the low normal limit. We speculate that the decrease in thyroid hormone level due to low TSH secretion happened just before the first admission, probably at the onset of sinuitis. This would explain why only T4 which has a longer half life than T3 remained within normal range. A short duration of low T3 level would also explain the normal concentration of serum cholesterol. The present case should be differentiated from hypothalamic hypothyroidism and non-thyroidal illness. The diagnosis of hypothalamic hypothyroidism was unlikely, because most patients with hypothalamic hypothyroidism have measurable or, occasionally, elevated basal levels of serum TSH, as well as a prolonged and/or exaggerated response to TRH (5). In the case of severe non-thyroidal illness, a diminished TSH response to TRH was reported, however, it has not been completely absent (6). Our patient presented undetectably low serum basal levels of TSH, T3 and no TSH increment after TRH injection. Thus,

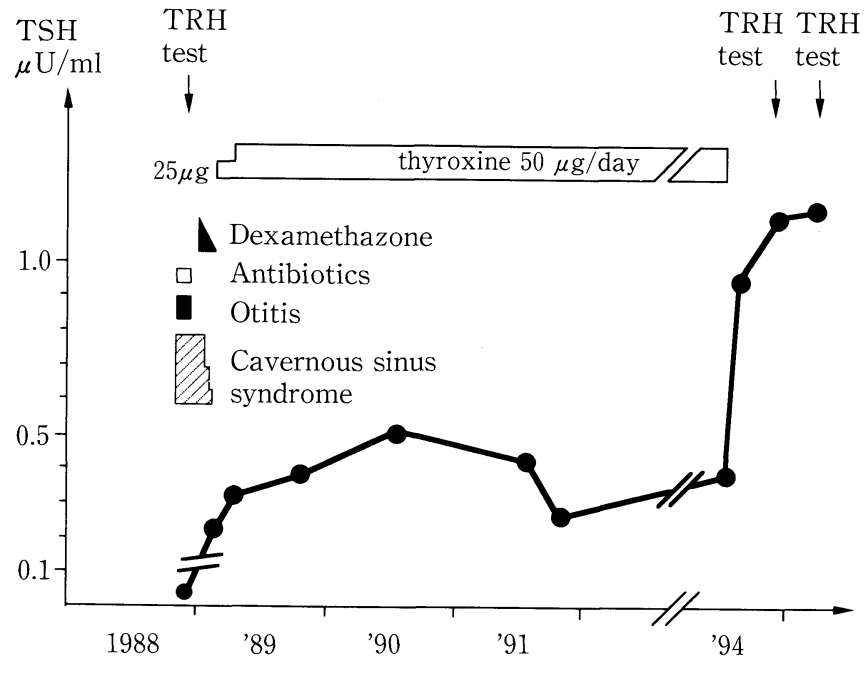

Figure 4. Clinical course and serum basal TSH level of the patient. Serum TSH level gradually increased after treatment. Dexamethazone was started on December 21, 1988. On July 12, 1994 , the patient was euthyroid without supplementation.

the data favor the diagnosis of pituitary TSH deficiency. The period in which the patient suffered from complete TSH deficiency is estimated to be very short, because three months after the diagnosis of TSH deficiency, the serum TSH concentration was low $(0.21 \mu \mathrm{U} / \mathrm{ml})$ but detectable (Fig. 4).

Isolated TSH deficiency is a rare entity whose etiologies reported thus far $(2,4,7-13)$ include genetic origins and pituitary tumors, but are unknown. Normal computed tomography (CT) and magnetic resonance imaging (MRI) studies in this case suggested that a pituitary tumor or an eosinophilic granuloma was not causing the disease. In the present case, however, causal relationships between the cavernous sinus syndrome and isolated TSH deficiency were suggested; 1) TSH deficiency and cavernous sinus syndrome were diagnosed simultaneously.2) Administration of dexamethasone improved the neurologic symptoms of cavernous sinus syndrome and increased the basal level of serum TSH, despite its suppressive effect on TSH secretion (14). Given their proximity, it is not difficult to suppose the causal relationship between sinusitis and TSH-deficiency. In the present case, the contribution of the otitis which was demonstrated by the increased ${ }^{99 \mathrm{~m}} \mathrm{Tc}$ uptake at the clivus and petrous bone on bone scan is apparent. The inflammation most likely extended from left otitis via the cavernous sinus, the main locus of inflammation. However, a normal MRI image does not support the direct involvement of inflammation in the pituitary gland. It is tempting to speculate that high concentrations of inflammatory cytokines which are produced locally suppress the hypothalamus and/or pituitary function (15) as is thought to happen in non-thyroidal illness (16). Why only thyrotrophs among other pituitary cells were susceptible to this process remains unknown.

Involvement of the cavernous sinus suggests a possible link to another pituitary disease; lymphocytic hypophysitis. Lym- 
phocytic hypophysitis presents in females during gestation or postpartum with various symptoms of hypopituitarism such as ACTH deficiency (17) and is associated with large parasellar masses on CT examination (18). Lymphocytic hypophysitis sometimes affects the elderly male people associated with cavernous sinusitis or hyperplastic meningitis (19). Despite the above-mentioned huge differences in "lymphocytic hypophysitis" in males and females, they are currently classified as a single entity. The present case is on the border between TSH deficiency and lymphocytic hypophysitis in male.

Finally, 2 weeks and 6 months after cessation of thyroxine supplement, basal serum levels of T3 and T4, and the TSH response to TRH were normal, demonstrating a complete recovery from TSH deficiency. Boehm et al (2) reported that thyroid hormone supplement facilitated TSH secretion in a patent with isolated TSH deficiency. However, in their patient, the TSH response to TRH remained very low and the serum T4 level was far below the normal limit 2 months after cessation of thyroxine supplement. Thus, it is difficult to support a transient nature of TSH deficiency in their case. Merenich et al (20) reported a patient with transient isolated TSH deficiency in the postpartum period. However, TRH challenge test was not performed in their case. Therefore, it is difficult to determine whether their patient had complete lack of TSH.

In conclusion, this report adds a new dimension to TSH deficiency and draws attention to the obscured lines between lymphocytic hypophysitis, cavernous sinus syndrome and isolated TSH deficiency. To our knowledge, this is the first report of isolated TSH-deficiency in association with cavernous sinus syndrome. Our observations suggest that some cases of TSH deficiency may resolve, and that follow-up of pituitary and thyroid function is warranted in order to avoid unnecessary T4 supplement.

\section{References}

1) Shuman CR. Hypothyroidism due to thyrotropin deficiency without other manifestations of hypopituitarism. J Clin Endocrinol Metab 13: 795, 1953.

2) Boehm TM, Dimond RC, Wartofsky L. Isolated thyrotropin deficiency with thyrotropin-releasing hormone induced TSH secretion and thyroidal release. J Clin Endocrinol Metab 43: 1041, 1976.
3) Odell WD. Isolated deficiencies of anterior pituitary hormones. Symptoms and diagnosis. JAMA 197: 1006, 1966.

4) Labbe A, Dubray C, Gaillard G, Besse G, Assali P, Malpuech G. Familial growth retardation with isolated thyroid-stimulating hormone deficiency. Clin Pediatr (Phila) 23: 675, 1984.

5) Beck-Peccoz P, Amr S, Menezes-Ferreira M, Faglia G, Weintraub BD. Decreased receptor binding of biologically inactive thyrotropin in central hypothyroidism. Effect of treatment with thyrotropin-releasing hormone. N Engl J Med 312: 1085, 1985.

6) Vierhapper H, Laggner A, Waldhausl W, Grubeck-Loebenstein B, Kleinberger G. Impaired secretion of TSH in critically ill patients with 'low T4-syndrome'. Acta Endocrinol (Copenh) 101: 542, 1982.

7) Miyai K, Azukizawa M, Kumahara Y. Familial isolated thyrotropin deficiency with creatinism. N Engl J Med 285: 1043, 1971.

8) Wakamoto H, Miyazaki M, Tatsumi K, Amino N. Thyroid ultrasonography in congenital isolated thyroid stimulating hormone deficiency. Arch Dis Child 72: 439, 1995.

9) Nygren A, Rojdmark S. Isolated thyrotropin deficiency in a man with narcoleptic attacks. Acta Med Scand 212: 175, 1982.

10) Sachson R, Rosen SW, Cuatrecasas P, Roth J, Frantz AG. Prolactin stimulation by thyrotropin-releasing hormone in a patient with isolated thyrotropin deficiency. N Engl J Med 287: 972, 1972.

11) Lee HB, Faiman C. Isolated thyrotropin deficiency due to a pituitary tumor. Can Med Assoc J 116: 520, 1977.

12) Burke CW, Moore RA, Rees LH, Bottazzo GF, Mashiter K, Bitensky L. Isolated ACTH deficiency and TSH deficiency in the adult. J R Soc Med 72: 328, 1979.

13) Hara Y, Sekiya M, Suzuki M, Hiwada K, Kato I, Kokubu T. A case of isolated thyrotropin deficiency with Cushing's syndrome. Jpn J Med 28: 727, 1989 .

14) Wilber JF, Utiger RD. The effect of glucocorticoids on thyrotropin secretion. J Clin Invest 48: 2096, 1969.

15) van Haasteren GA, van der Meer MJ, Hermus AR, et al. Different effects of continuous infusion of interleukin- 1 and interleukin- 6 on the hypothalamic-hypophysial-thyroid axis. Endocrinology 135: 1336, 1994.

16) Boelen A, Platvoet-Ter Schiphorst MC, Wiersinga WM. Association between serum interleukin-6 and serum 3,5,3'-triiodothyronine in nonthyroidal illness. J Clin Endocrinol Metab 77: 1695, 1993.

17) Hashimoto $\mathrm{K}$, Takao T, Makino S. Lymphocytic adenohypophysitis and lymphocytic infundibuloneurohypophysitis. Endocr J 44: 1, 1997.

18) Mathur S, Genco PV, Williamson HO, Koopman WR Jr, Rust PF, Fudenberg HH. Association of human leukocyte antigens B7 and BW35 with sperm antibodies. Fertil Steril 39: 343, 1983.

19) Pestell RG, Best JD, Alford FP. Lymphocytic hypophysitis. The clinical spectrum of the disorder and evidence for an autoimmune pathogenesis. Clin Endocrinol (Oxf) 33: 457, 1990 (see comments).

20) Merenich JA, McDermott MT, Kidd GS. Transient isolated thyrotropin deficiency in the postpartum period. Am J Med 86: 361, 1989. 